\title{
Parents' evaluation of support in Australian hospitals following stillbirth
}

Melanie L Basile, Einar B Thorsteinsson

The present study evaluated the level of support and satisfaction among parents of stillborn babies in Australian hospitals. One-hundred and eighty-nine mothers and fathers completed an online survey designed by the researcher based on the guidelines designed by the Perinatal Society of Australia and New Zealand. Support was inconsistent with guidelines implemented only $55 \%$ of the time, on average. Areas of support regarding creating memories, birth options and autopsy were most problematic. A significant positive correlation was found between support and satisfaction and there is indication that there has been some increase in support and satisfaction over time. There has been a significant increase in both support and satisfaction since the release of the guidelines in 2009.

Creating memories was regarded by parents as the most influential to their grief. It is recommended that health professionals review guidelines and seek feedback from parents as to how they can improve the support they provide. 
Melanie L. Basile

Please address correspondence to:

A/Prof. Einar B. Thorsteinsson

Australia

Phone: + 61267732587

Email: ethorste@une.edu.au 
Abstract

24 The present study evaluated the level of perceived support and satisfaction among parents of stillborn

25 babies in Australian hospitals. One-hundred and eighty-one mothers, six fathers, and two participants

26 without sex specification were recruited online via Facebook. Participants completed an online survey

27 designed by the researcher based on the guidelines designed by the Perinatal Society of Australia and

28 New Zealand. Perceived support was inconsistent with guidelines implemented only 55\% of the time,

29 on average. Areas of perceived support regarding creating memories, birth options, and autopsy were

30 most problematic. A significant positive correlation was found between perceived support and

31 satisfaction and there is an indication that there has been some increase in perceived support and

32 satisfaction over time. There has been a significant increase in both perceived support and satisfaction

33 since the release of the guidelines in 2009. Creating memories was regarded by parents as the most

34 influential to their grief. It is recommended that health professionals review guidelines and seek

35 feedback from parents as to how they can improve the support they provide.

36

37

38

39 


\section{Introduction}

\section{Scope of the Problem}

A stillbirth, as defined in Australia, is the death of a baby before or during birth at 20 weeks or more gestation, or with a birth weight of at least 400 grams (Li, Zeki, Hilder, \& Sullivan, 2013). In 2011, there were 2,200 stillbirths in Australia providing a rate of 7.4 stillbirths per 1,000 total births (Li et al., 2013).

Stillbirth is a unique loss in that it encompasses the loss of a person, loss of parenthood, and the loss of future hopes and dreams (Boyle, Vance, Najman, \& Thearle, 1996; Fetus and Newborn Committee, 2001; Kowalski, 1983; Robinson, Baker, \& Nackerud, 1999). This devastating loss is compounded by the lack of acknowledgement, validation, and support in the community (Bennett, Litz,

50 Lee, \& Maguen, 2005; Kowalski, 1983; McGreal, Evans, \& Burrows, 1997). The grief may extend into

51 future pregnancies and can last from months to years (Hutti, 2005). Mothers of stillborn babies are up

52 to three times more likely to develop anxiety and depression, and suffer significantly higher levels of

53 psychological distress compared with mothers of living infants (Boyle et al., 1996; Rådestad, Steineck,

54 Nordin, \& Sjögren, 1996). Feelings of shock, guilt, anger, anxiety, emptiness, loneliness, and

55

56

57 helplessness are often expressed as families are ill-prepared to deal with the intensity of their grief (Boyle et al., 1996; Callan \& Murray, 1989; Flenady, Boyle, Koopmans, Wilson, Stones, \& Cacciatore, 2014). Undermining the damage following a stillbirth leaves bereaved families to grieve in isolation and silence (Scott, 2011).

The Perinatal Society of Australia and New Zealand (PSANZ) have developed evidence-based guidelines to assist health professionals in providing relevant support for bereaved parents (Flenady et al., 2009). In an attempt to ensure that support in Australia is consistent and meeting the needs of bereaved parents, a thorough evaluation must take place. The current study aims to explore levels of 
63 perceived support and satisfaction in hospitals across Australia and to shed light on any areas of

64 support that need improvement.

\section{Background}

Before the 1960s, grief associated with stillbirth was unrecognised in the literature (Brabin, 2004). Stillborn babies were taken away and disposed of without any parental involvement and

68

Once health professionals realised that attachments were formed before birth during pregnancy, the significance of loss through stillbirth was recognised (Fetus and Newborn Committee, 2001; Leon, 1992; Robinson et al., 1999). As early as the 1970s Yates (1972) described how mothers of stillborn babies found it helpful to talk about their experiences and how naming the baby was important to them. Additionally, Lewis (1979) found that when hospital staff facilitated mourning there was better adjustment to bereavement.

It has been explained by Leon (1987) that interactions with the baby and the creation of concrete tokens of remembrance are at the very essence of parental mourning. Not only is the baby to be mourned but also the lost hopes and wishes for a future together, "it is the loss of one who will never be rather the loss of one who once was" (Leon, 1987, p. 194).

There is now great value placed on viewing, naming, and holding the baby in order to formulate an identity and validate the pregnancy and death (Aldridge, 2008; Bennett et al., 2005; Bonnette \& Broom, 2011; Callan \& Murray, 1989; Chance, Outerbridge, Beaudry, MacMurray, Pendray, \& Shea, 1983; Fetus and Newborn Committee, 2001; Hammersley \& Drinkwater, 1997; Leon, 1987). It is now commonplace to encourage families to take photographs of the deceased baby as a means of creating 
87 an identity for which the baby can be remembered and mourned (Godel, 2007). Photographs give the

88 baby social status as a family member and portrays them as a valued individual as well as helping the

89 parents recognise their roles as mother and father, which is often left unrecognised (Godel, 2007).

\section{Individualised Support}

It has been recommended that health professionals understand the significance of the loss for

92

93

94

95

96

97

98

99

100

101

102

103

104

105

106

107

108

109

110

each unique family as a way to offer appropriate support which should be "open, sensitive, and nondirective, and ultimately tailored..." (Lafarge, Mitchell, \& Fox, 2013, p. 933). Culture, religion, and traditions influence the way people mourn and sensitivity to the variety of beliefs and behaviours may help to facilitate bereavement (Bennett et al., 2005; Callan \& Murray, 1989; Chance et al., 1983;

Chichester, 2005; Cowchock, Ellstad, Meador, Koenig, Hooten, \& Swamy, 2011; Fetus and Newborn Committee, 2001). It is also important that health professionals do not allow their own personal beliefs to interfere with a family's style of grieving (Chichester, 2005; Flenady et al., 2014; Mahan \& Calica, 1997). Understanding the diversity of behaviours, practices, and beliefs held by different cultures will assist with supporting families, although it is advised that assumptions should never be made based on a family's appearance (Chichester, 2005). Some families may adhere to cultural norms while others may choose to honour their baby in a unique way (Chichester, 2005).

Similarly, it is important to recognise the different coping styles and grief patterns between mothers and fathers (McGreal et al., 1997). In a pilot study assessing sex differences following miscarriage or stillbirth, different rates and forms of grieving were found between mothers and fathers affecting communication and heightening feelings of vulnerability (McGreal et al., 1997). It has been found that fathers feel their grief is less significant in the eyes of hospital staff and therefore often feel overlooked and dissatisfied with treatment (Bonnette \& Broom, 2011). Mothers have even remarked how their partners were adversely affected by feeling excluded within the hospital post-loss (Sanchez, 2001). In a study by Säflund and Wredling (2006), mothers and fathers were found to rate the 
111 behaviour of the physician differently, with fathers finding them to be more insensitive than mothers.

112 In the vast majority of research in this area it is common to see only the reactions of mothers

113 documented (Callan \& Murray, 1989). Bonnette and Broom (2011) describe how the recognition and

114 validation of fatherly grief is often overshadowed by the view they are merely supportive partners.

115 Nature of Support Received

116 In 1982, Forrest, Standish, and Baum (1982) conducted a randomised trial comparing mothers

117 that received routine hospital care against mothers that received planned support (based on guidelines)

118 and counselling. Planned support and counselling was found to appreciably shorten the duration of

119 distress of bereaved mothers (Forrest et al., 1982). However, there is some concern about how

120 protocols and guidelines are handled and applied (Hutti, 2005; Leon, 1992). It is recommended that

121 care be taken to respect the individual wishes and needs of the family as standardization of

122 bereavement care runs the risk of disrupting a family's unique style of coping (Bennett et al., 2005).

123 Hospital support, or lack thereof, appears to have a significant impact on grief resolution (Gold,

124 2007; Kirkley-Best \& Kellner, 1982). Parents are able to recount distress caused by negative

125 experiences many years after the event showing how crucial it is that the level of support is meeting the

126 needs and expectations of parents (Cacciatore \& Bushfield, 2007; Downe, Schmidt, Kingdon, \&

127 Heazell, 2012; Lafarge et al., 2013). In a recent study by Crawley, Lomax, and Ayers (2013), mental

128 health outcomes of bereaved mothers could be predicted by the degree of perceived professional

129 support received. Similarly, Hammersley and Drinkwater (1997) found recognition of loss and

130 empathy by others to be powerful factors in alleviating pathological reactions to stillbirth.

131 With hospital guidelines now in place, there has been a call for more studies to examine the

132 level of support currently offered as well as measuring levels of satisfaction (Bennett et al., 2005;

133 Cacciatore \& Bushfield, 2007; Callan \& Murray, 1989; Erlandsson, Säflund, Wredling, \& Rådestad,

134 2011; Gold, 2007; Lasker \& Toedter, 2007; Wing, Burge-Callaway, Clance, \& Armistead, 2001).While 
135 some studies indicate that support provided within the hospital setting is satisfactory (Bennett, Litz,

136 Maguen, \& Ehrenreich, 2008; Conry \& Prinsloo, 2008; Geerinck-Vercammen \& Kanahi, 2003;

137 Lafarge et al., 2013), there is evidence that more consistent support is needed (Cacciatore \& Bushfield, 138 2007; Cacciatore, Schnebly, \& Froen, 2009; Conry \& Prinsloo, 2008; Gold, 2007; Lasker \& Toedter,

139 2007; Simwaka, de Kok, \& Chilemba, 2014). Here, bereaved parents are vital to bring about change by

140 "voicing their stories... and being heard, parents can undo some of the myths that surround stillbirth

141 and focus attention on how things could be done better." (Scott, 2011, p. 1388).

142 Perceived support from health professionals and the opportunity to create memories have been

143 documented as the most important factors in the way parents define their hospital experience (Conry \&

144 Prinsloo, 2008; Downe et al., 2012; Lafarge et al., 2013). Forrest et al. (1982) found that almost half of 145 mothers felt that support within the hospital settings could be improved and where care was judged as 146 satisfactory, flexibility had been mentioned as an important factor.

147 Lasker and Toedter (2007) completed one of the largest longitudinal studies assessing parents' 148 satisfaction with hospital care in the United States. They found that parents who received support were 149 more satisfied than parents that did not, although having more support did not lead to greater levels of 150 overall satisfaction. They suggest this is because quality of perceived support is also a determinant of 151 satisfaction and grief alleviation. Harper and Wisian (1994) have also documented a significant 152 positive relationship between satisfaction and the use of most recommended interventions. Variation in 153 the support offered by different health care professionals has also been reported, with doctors often 154 being described as not meeting the emotional needs of parents (Cacciatore et al., 2009; Erlandsson et 155 al., 2011; Gold, 2007). In Australia, Brabin (2004) discusses how the Stillbirth and Neonatal Death

156 Support (SANDS) charity has reported a shift over the last 20 years with fewer complaints regarding 157 hospital support and an increase with the satisfaction of care. In the UK, parents that had worked 158 collaboratively with health professionals were able to create bereavement support that "respects 
159 parents' needs, acknowledging that stillbirths matter and that the quality of care grieving parents 160 receive can have a lifelong effect..." (Scott, 2011, p. 1388).

161 Very little research of a quantitative nature has been employed to assess parents' level of 162 perceived support and whether the support received is satisfactory. The majority of studies have also

163 used very small sample sizes and have evaluated only one hospital service. Furthermore, only a limited

164 number of studies have assessed the experiences of both mothers and fathers. No studies have

165 examined the support offered in Australian hospitals and whether parents of stillborn babies have

166 found such support satisfactory (perceived support). Additionally, limited studies have examined

167 differences in perceived support and satisfaction following the introduction of the PSANZ guidelines.

168 The current study aims to address these shortcomings.

169 Although designed to be non-prescriptive, the PSANZ guidelines have been used by the current

170 study as a benchmark to examine the support offered to parents of stillborn babies in Australian

171 hospitals. These guidelines are designed to provide knowledge to Australian and New Zealand health

172 professionals by describing generally recommended practice and to enhance the quality of bereavement

173 care (Flenady et al., 2009). Following the recommendations of the National Health and Medical

174 Research Council, the guidelines were developed by searching for existing guidelines and completing a

175 comprehensive literature review (Flenady et al., 2009). Support offered is used in the current study as

176 the collective term to include the hospital practices and interventions (guidelines) relevant to stillbirth

177 under the following categories: respect, information, autopsy, birth options, hospital stay, creating

178 memories, and aftercare. By examining levels of perceived support and satisfaction it is hoped that the

179 research will shed light on any areas that need improvement.

180 The present study aims:

181 1. To assess the level of perceived support parents are receiving (as determined by the PSANZ 182 guidelines) and the extent of parent satisfaction. 
183

184

185

186

\section{Participants}

193

2. To identify if the introduction of the PSANZ guidelines has significantly increased levels of perceived support and parent satisfaction and whether there is a negative correlation between years since birth and support and satisfaction.

3. To examine the extent to which perceived support is positively correlated with parent satisfaction and to explore which areas of support parents perceive to be most influential to their grief.

4. To determine if fathers are receiving a lower level of perceived support and are less satisfied than mothers.

\section{Method}

Participants were at least 18 years old and were parents of stillborn babies born in an Australian

hospital. A stillbirth occurs when a baby dies at 20 weeks or more gestation or with a birth weight of at least 400 grams. Participants were asked about gestation but not birth weight. Two participants, who gave birth on or before 12 weeks gestation, where it was reasonable to assume they had a miscarriage as opposed to a stillbirth, were excluded. One-hundred and forty-eight participants were excluded as they answered very few survey questions while one participant was excluded because she gave birth outside of Australia.

The sample consisted of 181 women $(95.8 \%)$, six men (3.2\%), and two (1.1\%) who did not indicate if they were a woman or a man. Age ranged from 18 to 65 years $(M=34.9, S D=7.6)$. The majority of participants were married/de facto (84.1\%) and generally well educated with $41.8 \%$ having completed a university degree or higher.

Years since birth ranged from zero to 40 years $(M=5.0, S D=6.4)$ and time of birth ranged from 16 to 42 weeks gestation $(M=30.5, S D=7.5)$. Location of birth covered all states and territories across Australia: New South Wales (32.3\%), Victoria (28.6\%), Queensland (18.0\%), Western Australia 
207 (9.0\%), South Australia (5.8\%), Australian Capital Territory (2.6\%), Tasmania (2.6\%), and Northern

208 Territory (1.1\%). According to the data collected by Australia's Mothers and Babies 2011 (Li et al.,

209 2011), this is a fairly accurate cross-section of the population. Participants in the study gave birth in 96

210 different hospitals across Australia with $82.5 \%$ being public and $17.5 \%$ being private. One-hundred

211 and thirty-three participants were admitted as public patients (70.4\%), 54 were admitted as private

212 patients (28.6\%), and two did not report patient admission status (1.1\%). A total of $174(92.1 \%)$, of the

213 pregnancies were single, with 14 (7.4\%), being a multiple pregnancy, and one (0.5\%), participant

214 failing to report. Of the multiple pregnancies, nine participants reported a loss of one baby, while five

215 reported a loss of more than one.

216 Procedure

217 The study was conducted with the approval of the Human Research Ethics Committee of the

218 University of New England, Australia, approval number HE14-149. Participants were recruited online

219 via Facebook where approval was sought from page administrators for a link to the Stillbirth Support

220 Survey to be posted on the page. Pages were selected by searching key words such as "stillbirth,"

221 "stillborn," and "pregnancy loss" and any linked and suggested pages on the chosen pages were also

222 explored. The pages included closed groups, open groups, non-profit organisations, communities,

223 charity organisations, and public figures. Of the 27 pages approached seven agreed to participate. The

224 link was voluntarily shared on other pages, recommended to specific individuals, and displayed on one

225 counselling website.

226 Potential participants who followed the link were forwarded to the Stillbirth Support Survey

227 powered by Qualtrics software (Qualtrics, 2014). An information sheet was initially provided followed

228 by an online implied consent form where potential participants could choose to proceed or exit the

229 study. If participants chose to proceed then they were given survey instructions before going on to

230 complete the Stillbirth Support Survey. If a participant had experienced more than one stillbirth from 
231 separate pregnancies questions were to be answered based on the most recent experience. If a particular

232 question was not relevant or if participants could not recall if something did or did not happen they

233 were advised to leave the item blank. To reduce the risk of emotional trauma participants were

234 reminded that they were able to withdraw from the survey at any stage and information for

235 bereavement counselling was made available at the beginning and end of the survey.

236 Materials

Participants volunteered to complete the Stillbirth Support Survey designed by the researcher.

238 The survey consisted of 12 demographic and topic-specific questions followed by 50 questions

239 assessing perceived support as per the PSANZ guidelines. Here perceived support was measured under

240 the following categories: respect, information, autopsy, birth options, hospital stay, creating memories,

241 and aftercare. Participants were presented with a statement and asked to answer on a 5-point scale $(1=$

242 strongly disagree to 5 = strongly agree). Example items include: "My cultural/religious beliefs,

243 traditions and practices were respected by hospital staff," "The information I received was delivered in

244 a sensitive manner," and "I was provided with an opportunity to bathe my baby/babies." Participants

245 were asked how satisfied they were with the overall level of perceived support on a 7 -point scale $(1=$

246 very dissatisfied to $7=$ very satisfied), and then asked which area(s) of support they felt were most

247 influential to their grief process (respect, information, autopsy, birth options, hospital stay, creating

248 memories, aftercare, and other). The perceived support and satisfaction measures where collapsed (i.e.

249 "agree" and "strongly agree" were merged into one) for Aim 1 to assist the interpretation of results.

250 No reportable measures of reliability and validity are available for the Stillbirth Support

251 Survey. Questions were based directly on the published PSANZ guidelines which are intended as

252 generally recommended practice for Australia and New Zealand (Flenady et al., 2009). 


\section{Statistical Analysis}

Pearson's correlation coefficient and independent $t$-tests were used to analyse the data.

Assumptions of normality, independence, and homogeneity of variance were met for the "satisfaction" and "perceived support" variables. Due to positive skewness and kurtosis of the "years since birth" variable a $\log +1$ transformation was conducted as per Field's (2005) recommendation. There was little difference between results for raw and transformed data thus raw data results were retained for ease of interpretation.

Results

\section{Perceived Support (Aim 1)}

Descriptive statistics were used to assess levels of perceived support (as determined by the PSANZ guidelines). Participants who indicated either agree or strongly agree on support items were combined to determine the extent to which guidelines are being followed in Australian hospitals. Table 1 provides a summary these findings.

\section{Parent Satisfaction (Aim 1)}

Descriptive statistics were used to assess the amount of satisfaction among parents of stillborn babies. In total, of the 189 participants, $64.0 \%$ reported satisfaction with their overall level of perceived hospital support. There were $30.2 \%$ reports of dissatisfaction and $5.8 \%$ of participants remained neutral.

\section{The Effect of the PSANZ Guidelines on Support and Satisfaction (Aim 2)}

The PSANZ guidelines were published in 2009 so the participants were split into two groups based on whether participants gave birth before or after the release of the material. Mean scores for perceived support and satisfaction are provided in Table 2.

On average, parents who gave birth after 2009 reported greater perceived support $(M=3.51, S E$

$276=0.07)$, than parents who gave birth before $2009(M=3.12, S E=0.12), t(186)=3.12, p<.001$ with a 
small to medium sized effect $r=.22$. Similarly, parents who gave birth after 2009 also reported higher satisfaction $(M=5.11, S E=0.17)$ than parents who gave birth before $2009(M=4.09, S E=0.29)$, $t(186)=3.16, p<.001$ with a small to medium sized effect $r=.23$. A description of satisfaction frequencies and percentages between groups is provided in Table 3.

\section{Perceived support and Satisfaction over Time (Aim 2)}

Pearson's correlation coefficient was used to determine whether there was a negative relationship between perceived support, satisfaction, and years since birth. Perceived support was negatively correlated to years since birth, with a coefficient of $r=-.33$, which was also significant at $p$

$<.01$. A negative relationship was also documented between satisfaction and years since birth $(r=-.31$, $p<.01)$

\section{Relationship between Perceived support and Satisfaction and Influences on Grief (Aim 3)}

Pearson's correlation coefficient was also used to determine if there was a positive relationship between perceived support and satisfaction. A significant relationship was found, $r=.89, p<.01$.

Descriptive statistics were used to explore which areas of perceived support parents perceived to be most influential to their grief, see Table 4. Over half of the participants reported creating memories, respect, and hospital stay to be the most influential.

\section{Differences between Mothers and Fathers (Aim 4)}

The sample did not enable a meaningful comparison of mothers and fathers given the small sample of fathers.

\section{Discussion}

The current study aimed to assess the level of perceived support parents are receiving (as determined by the PSANZ guidelines) and the extent of parent satisfaction. Over the last 40 years Australian hospitals have provided some relevant support to bereaved parents of stillborn babies, however, much improvement is needed. While some guidelines are being demonstrated in up to $93.1 \%$ 
301 of cases, others are rarely displayed (as low as 6.3\%). On average, guidelines are being implemented 302 just over $55 \%$ of the time. Overall, areas of perceived support that are the strongest include respect, 303 information, hospital stay, and after care, with birth options, creating memories, and autopsy being the 304 lowest scoring categories on average. It is evident that there is considerable variance in terms of 305 support with some bereaved parents being offered specific interventions and practices while others are 306 not. For instance, some parents are missing out on important information, opportunities with their 307 deceased baby/babies, and options regarding their care. Overall, of the 189 participants that gave birth 308 between 1974 and 2014, 64\% reported satisfaction with the overall level of perceived support. As expected, a significant increase in both perceived support and parent satisfaction was found 310 since the publication of the PSANZ guidelines in 2009. Further support for guidelines has been found 311 in the UK where the duration of distress was noticeably shortened with the introduction of guidelines 312 and counselling (Forrest et al., 1982).

313 Of the participants who gave birth prior to $2009,46.5 \%$ reported some degree of dissatisfaction 314 compared to only $23.5 \%$ of participants who gave birth after 2009 . Although this is a marked decrease, 315 this means that almost one in four bereaved parents leave the hospital not only mourning the loss of 316 their child, but disappointed with the support provided to them at one of the most difficult times of 317 their lives. These findings are not dissimilar to other recent studies which have reports of support still 318 being inadequate, inconsistent, and unsatisfactory for some bereaved parents (Bonnette \& Broom, 319 2011; Cacciatore \& Bushfield, 2007; Conry \& Prinsloo, 2008; Downe et al., 2012; Erlandsson et al., 320 2011; Lafarge et al., 2013; Simwaka et al., 2014). Distress caused by negative experiences can be long321 lasting which indicates how crucial it is that all bereaved parents are adequately supported (Cacciatore 322 \& Bushfield, 2007; Downe et al., 2012; Kirkley-Best \& Kellner, 1982; Lafarge et al., 2013). As hypothesised, perceived support and satisfaction were negatively correlated with years since

324 birth. This suggests that there has been some improvement of support, and higher rates of satisfaction, 
325 over time. These results confirm reports that there have been far fewer complaints and greater

326 satisfaction among parents of stillborn infants in Australia over the last 20 years (Brabin, 2004).

327 Midwives have embraced training opportunities (Brabin, 2004) so it is hoped that as health

328 professionals continue to become more experienced and knowledgeable, improvements will continue

329 to be seen.

330 As hypothesised, a significant and strong positive relationship between perceived support and

331 parent satisfaction was documented. It seems likely that as health professionals adhere to the guidelines

332 provided by PSANZ, greater satisfaction will be seen among bereaved parents. However, a direct

333 causal relationship cannot be determined by the present study. In the United States, Harper and Wisian

334 (1994) also documented support for guidelines with satisfaction increasing with most recommended

335 practices. Although the guidelines are designed to be non-prescriptive, the results suggest that

336 following the recommendations by PSANZ may have a positive impact on bereaved parents.

337 The study also sought to explore which areas of support parents perceive to be most influential

338 to their grief. Three quarters of participants deemed creating memories (time with baby/babies,

339 mementoes, and baptism/blessing) to be the most influential area of support. Around half of the

340 participants also reported respect (for baby, parents, and cultural/religious beliefs), hospital stay

341 (environment, support of staff), after care (maternal changes, support services, referrals, and

342 expectations of grief), and information (timing, delivery, mode, and terminology) to be most influential

343 to their grief. These results support previous research that claims the creation of quality memories is

344 highly valued among bereaved parents (Bonnette \& Broom, 2011; Conry \& Prinsloo, 2008; Crawley et

345 al., 2013; Godel, 2007; Lafarge et al., 2013; Lasker \& Toedter, 2007). Additionally, the quality of

346 memories has been found to dictate whether the experience was viewed as either positive or negative

347 (Downe et al., 2012). The creation of memories further assists in creating an identity for the deceased

348 as well as validating the pregnancy and the loss (Aldridge, 2008; Bennett et al., 2005; Bonnette \& 
349 Broom, 2011; Callan \& Murray, 1989; Chance et al., 1983; Fetus and Newborn Committee, 2001;

350 Hammersley \& Drinkwater, 1997; Leon, 1987). Furthermore, sharing memories has been associated

351 with fewer symptoms of post-traumatic stress disorder (Crawley et al., 2013).

With such a high value placed on creating memories by parents and the associated benefits to mental health (Crawley et al., 2013; Rådestad et al., 1996), it is a concern that this category was one of

354 the lowest scoring in terms of perceived support. This highlights that considerable changes need to be made by health professionals to ensure that support is consistent, relevant, and meeting the needs and expectations of bereaved parents.

\section{Limitations}

The sample may have been skewed given that it was predominantly younger, female, married, and well-educated. All participants also had internet access. Given that stillbirth affects a very small percentage of the population, there is difficulty in the recruiting of participants, however, future research should seek to engage a more diverse and representative sample. The use of some online support groups used for recruitment may have introduced bias. Participants were asked to comment retrospectively so there is also the potential for recall bias in the rating of experiences. However, it appears that although parents were informed to leave items blank if they could not remember or were unsure, many were still able to recount experiences from many years ago.

The recruitment process may have biased the diversity of the sample. Although attempts were made to include male participants by seeking support groups for fathers, the majority of pages that accepted participation were support groups for mothers Additionally, $\mathrm{i}$ has been documented that while women are more expressive, men tend to exert more control over their emotions and are expected to

370 keep their feelings to themselves (Stinson, Lasker, Lohmann, \& Toedter, 1992; Wing et al., 2001).

371 Such attitudes may have impacted self-inclusion rates among fathers in the current study. Furthermore, 372 it has been reported that finding a sense of belonging is the foremost coping strategy used by mothers 
373 of stillborn babies (McGreal et al., 1997). It may be that more mothers than fathers sought out the

374 selected pages on Facebook (where the survey was advertised) as a way of connecting with others and

375 dealing with their grief. An alternate method of recruitment is advised for future studies aiming to

376 include male participants.

377 It is possible that participants may have previously been satisfied with hospital support until

378 completing the Stillbirth Support Survey. Participants may have been unaware of specific interventions

379 and practices that could have been offered which in turn may have lowered their original perceptions of

380 the support they received. Future research in this area could evaluate satisfaction at the beginning and

381 end of the questionnaire to determine if perceptions are altered.

Furthermore, the study reports on experiences up to 40 years ago where it is recognised that

parental and societal expectations would have differed from today. However, even in the early 1970s

research was highlighting the benefits of seeing the baby, talking about the loss, naming the baby, and

having a private room following the birth (Yates, 1972). In an attempt to report whether guidelines are making a difference to perceived support and satisfaction, it was important to gather data on experiences before and after the PSANZ guidelines were released. It was also important to represent the mothers and fathers who gave birth to a stillborn baby many years ago and had a traumatic experience due to the lack of perceived support.

\section{Conclusion}

Although perceived support for bereaved parents in Australia has improved since the

392 introduction of the PSANZ guidelines, it is clear that hospitals are not implementing them fully.

393 However, it is unclear why this is happening. It may be that there is still knowledge lacking among

394 health professionals, or perhaps it is due to insufficient training and review processes.

Parents in the current study reported higher levels of satisfaction when hospitals were following 396 the recommendations. Creating memories was regarded as the most influential area of support by most 
397 participants, however, it was one of the categories most lacking support. It is recommended that health 398 professionals within the hospital environment review guidelines that are in place and seek feedback

399 from parents as to how support can be improved.

400 
Aldridge, A. (2008). Perinatal loss- a life-changing experience. Bereavement Care, 27, 23-23. doi:10.1080/02682620808657715

404

405

406

407

408

409

410

411

412

413

Bennett, S. M., Litz, B. T., Lee, B. S., \& Maguen, S. (2005). The scope and impact of perinatal loss: current status and future directions. Journal of Professional Psychology: Research and Practice, 36, 180-187. doi:10.1037/0735-7028.36.2.180

Bennett, S. M., Litz, B. T., Maguen, S., \& Ehrenreich, J. T. (2008). An exploratory study of the psychological impact and clinical care of perinatal loss. Journal of Loss and Trauma: International Perspectives on Stress and Coping, 13, 485-510. doi:10.1080/15325020802171268

Bonnette, S., \& Broom, A. (2011). On grief, fathering and the male role in men's accounts of stillbirth. Journal of Sociology, 48, 248-265. doi:10.1177/1440783311413485

Boyle, F. J., Vance, J. C., Najman, J. M., \& Thearle, M. J. (1996). The mental health impact of stillbirth, neonatal death or SIDS; prevalence and patterns of distress among mothers. Social Science and Medicine, 43, 1273-1282. doi:10.1016/0277-9536(96)00039-1

Brabin, P. (2004). To see, or not to see, that is the question. Challenging good-practice bereavement care after a baby is stillborn: the case in Australia. Grief Matters, 7, 28-33. Retrieved from http://search.informit.com.au/documentSummary;dn=283004235273696;res=IELFSC

Cacciatore, J., \& Bushfield, S. (2007). Stillbirth: The mothers' experience and implications for improving care. Journal of Social Work in End-Of-Life and Palliative Care, 3, 59-79. doi:10.1300/J457v03n03_06

Cacciatore, J., Schnebly, S., \& Froen, J. F. (2009). The effects of social support on maternal anxiety and depression after stillbirth. Health and Social Care in the Community, 17, 167-176. doi:10.1111/j.1365-2524.2008.00814.x 
425 Callan, V. J., \& Murray, J. (1989). The role of therapists in helping couples cope with stillbirth and newborn death. Family Relations, 3, 248-253. Retrieved from http://www.jstor.org/discover/210.2307/585048?uid=3737536\&uid=3737532\&uid=3737534\&s $\underline{\mathrm{id}=21104229987947}$

Chance, G. W., Outerbridge, E. W., Beaudry, M. A., MacMurray, B., Pendray, M. R., \& Shea, R. (1983). Support for parents experiencing perinatal loss. Canadian Medical Association Journal, 129, 335-339. Retrieved from http://www.cmaj.ca/content/129/334/335.abstract.

Chichester, M. (2005). Multicultural issues in perinatal loss. The Association of Women's Health, Obstetric and Neonatal Nurses, 9, 314-320. doi:10.1177/1091592305280875

Conry, J., \& Prinsloo, C. (2008). Mothers' access to supportive hospital services after the loss of a baby through stillbirth or neonatal death. Health Sa Gesondheid, 13, 14-24. Retrieved from $\underline{\text { http://hdl.handle.net/2263/6283 }}$

Cowchock, F. S., Ellstad, S. E., Meador, K. G., Koenig, H. G., Hooten, E. G., \& Swamy, G. K. (2011). Religiosity is an important part of coping with grief in pregnancy after a traumatic second trimester loss. Journal of Religious Health, 50, 901-910. doi:10.1007/s10943-011-9528-y

Crawley, R., Lomax, S., \& Ayers, S. (2013). Recovering from stillbirth: The effects of making and sharing memories on maternal mental health. Journal of Reproductive and Infant Psychology, 31, 195-207. doi:10.1080/02646838.2013.795216

Downe, S., Schmidt, E., Kingdon, C., \& Heazell, A. E. P. (2012). Bereaved parents' experiences of stillbirth in UK hospitals: a qualitative interview study. The British Medical Journal, 3, 1-10. doi:10.1136/bmjopen-2012-002237

Erlandsson, K., Säflund, K., Wredling, R., \& Rådestad, I. (2011). Support after stillbirth and its effect on parental grief over time. Journal of Social Work in End-Of-Life and Palliative Care, 7, 139152. doi:10.108411340/15524256.2011.593152 
449 Fetus and Newborn Committee. (2001). Guidelines for health care professionals supporting families experiencing a perinatal loss. Paediatric Child Health, 6, 469-477. Retrieved from http://www.ncbi.nlm.nih.gov/pmc/articles/PMC2807762/

452 Field, A. (2005). Discovering statistics using SPSS. London: SAGE.

453 Flenady, V., Boyle, F., Koopmans, L., Wilson, T., Stones, W., \& Cacciatore, J. (2014). Meeting the 454 needs of parents after a stillbirth or neonatal death. British Journal of Obstetrics and Gynaecology, 121, 137-140. doi:10.1111/1471-0528.13009

456 clinical guideline for perinatal mortality (Version 2.2). The Perinatal Society of Australia and New Zealand (PSANZ) Perinatal Mortality Group, Brisbane, Australia. Retrieved from http://www.stillbirthalliance.org.au/guideline1.htm.

Forrest, G. C., Standish, E., \& Baum, J. D. (1982). Support after perinatal death: a study of support and counselling after perinatal bereavement. British Medical Journal, 285, 1475-1479. Retrieved from http://www.ncbi.nlm.nih.gov/pmc/articles/PMC1500632/

Geerinck-Vercammen, C. R., \& Kanahi, H. H. (2003). Coping with termination of pregnancy for fetal abnormality in a supportive environment. Prenatal Diagnosis, 23, 543-548. doi:10.1002/pd.636

Godel, M. (2007). Images of stillbirth; memory, mourning and memorial. Visual Studies, 22, 253-269. doi:10.1080/14725860701657159

Gold, K. (2007). Navigating care after a baby dies: a systematic review of parent experiences with health providers. Journal of Perinatology, 27, 230-237. doi:10.1038/sj.jp.7211676

Hammersley, L., \& Drinkwater, C. (1997). The prevention of psychological morbidity following perinatal death. British Journal of General Practice, 47, 583-586. Retrieved from http://bjgp.org/content/547/422/583.short 
472 Harper, M. B., \& Wisian, N. B. (1994). Care of bereaved parents. A study of patient satisfaction.

473

474

475

476

477

478

479

480

481

482

483

484

485

486

487

488

489

490

491

492

493

494

Journal of Reproductive Medicine, 39, 80-86. Retrieved from

http://www.ncbi.nlm.nih.gov/pubmed/8169934

Hutti, M. H. (2005). Social and professional support needs of families after perinatal loss. Journal of Obstetric, Gynaecologic and Neonatal Nursing, 34, 630-638. doi:10.1177/0884217505279998

Kirkley-Best, E., \& Kellner, K. R. (1982). The forgotten grief: A review of the psychology of stillbirth. American Journal of Orthopsychiatry, 52, 420-429. doi:10.1111/j.1939-0025.1982.tb01428.x

Kowalski, K. (1983). When birth becomes death. Journal of the Association of Perioperative Registered Nurses, 38, 57-64. doi:10.1016/S0001-2092(07)69540-4

Lafarge, C., Mitchell, K., \& Fox, P. (2013). Women's experiences of coping with pregnancy termination for fetal abnormality. Qualitative Health Research, 23, 924-936. doi: $10.1177 / 1049732313484198$

Lasker, J. N., \& Toedter, L. J. (2007). Satisfaction with hospital care and interventions after pregnancy loss. Death Studies, 18, 41-64. doi:10.1080/07481189408252642

Leon, I. G. (1987). Short-term psychotherapy for perinatal loss. Psychotherapy, 24, 186-195. doi:10.1037/h0085703

Leon, I. G. (1992). Perinatal loss: A critique of current hospital practices. Journal of Clinical Pediatrics, 31, 366-374. doi:10.1177/000992289203100611

Lewis, E. (1979). Mourning by the family after a stillbirth or neonatal death. Archives of Disease in Childhood, 54, 303-306. doi:10.1136/adc.54.4.303

Li, Z., Zeki, R., Hilder, L., \& Sullivan, E. A. (2013). Australia’s mothers and babies 2011. Perinatal Statistics Series, 28, PER 59. Canberra: AIHW. National Perinatal Epidemiology and Statistics Unit. 
495 Mahan, C. K., \& Calica, J. (1997). Perinatal loss: Considerations in social work practice. Social Work in Health Care, 24, 141-152. doi:10.1300/J010v24n03_12

497 McGreal, D., Evans, B. J., \& Burrows, G. D. (1997). Gender differences in coping following loss of a child through miscarriage or stillbirth: A pilot study. Journal of Stress Medicine, 13, 159-165. doi:10.1002/(SICI)1099-1700(199707) influence of memories and immediate management: population based study. British Medical Journal, 213, 1505-1508. doi:10.1136/bmj.312.7045.1505

Robinson, M., Baker, L., \& Nackerud, L. (1999). The relationship of attachment theory and perinatal loss. Death Studies, 23, 257. doi:10.1080/074811899201073

Säflund, K., \& Wredling, R. (2006). Differences within couples' experience of their hospital care and well-being three months after experiencing a stillbirth. Acta Obstetricia et Gynecologica, 85, 1193-1199. doi:10.1080/00016340600804605

Sanchez, N. A. (2001). Mothers' perceptions of benefits of perinatal loss support offered at a major university hospital. The Journal of Perinatal Education, 10, 23-30. doi:10.1624/105812401X88165

515 Simwaka, A., de Kok, B., \& Chilemba, W. (2014). Women's perceptions of nurse-midwives caring behaviours during perinatal loss in Lilongwe, Malawi: An exploratory study. Malawi Medical Journal, 26, 8-11. Retrieved from http://www.ncbi.nlm.nih.gov/pmc/articles/PMC4062777/ 
518 Stinson, K., Lasker, J., Lohmann, J., \& Toedter, L. (1992). Parents' grief following pregnancy loss: a comparison of mothers and fathers. Family Relations, 41, 218-223. doi:10.2307/584836

520 Wing, D., Burge-Callaway, K., Clance, P., \& Armistead, L. (2001). Understanding gender differences 521 in bereavement following the death of an infant: implications for treatment. Psychotherapy, 38, 60-73. Retrieved from http://search.proquest.com.ezproxy.une.edu.au/docview/614353694/fulltextPDF/E614353691D $\underline{\text { FC614353529A614353641A614353693PQ/614353691?accountid }=614317227}$

525 Yates, S. A. (1972). Stillbirth: What a staff can do. The American Journal of Nursing, 72, 1592-1594. Retrieved from 


\section{Table $\mathbf{1}$ (on next page)}

Percentage of Participants that 'agree' or 'strongly agree' on the Different Support Items as per the PSANZ Guideline

Table 1 - Percentage of Participants that 'agree' or 'strongly agree' on the Different Support Items as per the PSANZ Guideline 
2 Table 1

3 Percentage of Participants that 'agree' or 'strongly agree' on the Different Support Items as per the

4 PSANZ Guideline

\begin{tabular}{lc}
\hline Measure & $\%$ \\
\hline
\end{tabular}

Respect

Respect to baby/babies

$\begin{array}{lr}\text { Respect to cultural/religious beliefs } & 71.0\end{array}$

Grief validated by hospital staff $\quad 74.0$

$\begin{array}{ll}\text { Supported to reach own decisions } & 66.5\end{array}$

To both parents

73.0

Sensitively

75.2

Honestly

75.7

Clearly

67.7

Appropriate terminology

78.6

In a quiet private place

81.5

Appropriate time

58.2

Written fact sheets

66.5

Consider information

Adequate time to

Ask questions

55.5

Grieve silently

63.5

68.8

Hospital staff

Made sure that parents understood the information provided

69.2

Spoke of the baby/babies in sensitive terms

75.7

Autopsy

Verbal and written options for post-mortem

63.0

Informed that results might take months to return and that noting

66.3 adverse may actually be found

Received information in a quite private place

58.6

Felt comfortable with the person delivering the information who could

52.4 competently answer questions

Knew the person taking their baby/babies to autopsy

11.1

Given opportunity to meet the pathologist and assured their baby/babies would be treated with respect

Given the option to see/hold their baby/babies after the autopsy

\section{Birth Options}

Given relevant information regarding delivery

Provided with a choice to remain in hospital or return home prior to delivery

Provided with information on the benefits and consequences of each

40.5 
type of delivery (natural vs. caesarean section)

Offered a choice in birth options

Asked to select a ward

Hospital environment

Provided with a private room

Away from the busiest part of the ward

93.1

Symbol placed on their door

55.0

Continuity of care

39.9

60.3

Time available with their baby/babies

85.7

Staff member available to collect/return baby/babies as desired 57.1

Informed that there was no urgency to leave the hospital $\quad 59.8$

Social worker provide support, counselling and information

57.2

Opportunities to create memories

Informed participants the length of time they could spend with their baby/babies

Gave option to stay in hospital or take their baby/babies home

17.0

Informed what to expect in terms of the appearance of their baby/babies

Made participants aware that there was no urgency to arrange a funeral

Informed participants that a baptism/blessing could be arranged if desired

Bathe their baby/babies

Had staff provide hand and footprints/ID bracelet/photographs/cot

86.7 cards

Had staff make suggestions of the creation of memories

Perceived after care support

Informed about milk production and was given the option of a lactation consultant

Made aware of post-pregnancy changes and the need for a post-birth check-up

Received information and referrals to other relevant health professionals

Informed of the legal requirement to arrange a funeral and given options for funeral arrangements

Told what to expect in terms of the grief process 
Table 2 (on next page)

Mean Scores on the Stillbirth Support Survey $<!--N \& \mid 2$

Table 2 - Mean Scores on the Stillbirth Support Survey $<!--\%$ 
2 Table 2

3 Mean Scores on the Stillbirth Support Survey

\begin{tabular}{|c|c|c|c|c|}
\hline \multirow[b]{2}{*}{ Measure } & \multicolumn{2}{|c|}{$\begin{array}{c}\text { Births from } \\
1974-2008 \\
(n=56)\end{array}$} & \multicolumn{2}{|c|}{$\begin{array}{c}\text { Births from } \\
2009-2014 \\
(n=132)\end{array}$} \\
\hline & $M$ & $S D$ & $M$ & $S D$ \\
\hline Respect (4) & 3.67 & 1.08 & 3.98 & 1.01 \\
\hline Information (13) & 3.39 & 1.04 & 3.83 & 0.93 \\
\hline Autopsy (7) & 2.81 & 0.83 & 3.19 & 0.80 \\
\hline Birth options (4) & 2.68 & 1.07 & 3.03 & 0.96 \\
\hline Hospital Stay (9) & 3.10 & 0.93 & 3.60 & 0.85 \\
\hline Creating Memories (8) & 2.84 & 0.92 & 3.18 & 0.83 \\
\hline Aftercare (5) & 3.10 & 1.01 & 3.48 & 0.96 \\
\hline $\begin{array}{l}\text { Total Perceived Support } \\
\text { Score }(50)\end{array}$ & 3.12 & 0.87 & 3.51 & 0.75 \\
\hline Satisfaction (1) & 4.09 & 2.17 & 5.11 & 1.97 \\
\hline
\end{tabular}

4 Note. Perceived support scores could range from 1 (strongly disagree) to 5 (strongly agree), and

5 satisfaction scores ranged from 1 (very dissatisfied) to 7 (very satisfied). Number of items for each 6 measure is displayed in parentheses. 
Table 3 (on next page)

Satisfaction Frequencies and Percentages in Relation to Guidelines

Table 3 - Satisfaction Frequencies and Percentages in Relation to Guidelines 
2 Table 3

3 Satisfaction Frequencies and Percentages in Relation to Guidelines

\begin{tabular}{|c|c|c|c|c|}
\hline \multirow[b]{2}{*}{ Satisfaction } & \multicolumn{2}{|c|}{$\begin{array}{c}\text { Births from } \\
1974-2008 \\
(n=56)\end{array}$} & \multicolumn{2}{|c|}{$\begin{array}{c}\text { Births from } \\
2009-2014 \\
(n=132)\end{array}$} \\
\hline & Frequency & $\%$ & Frequency & $\%$ \\
\hline Very dissatisfied & 8 & 14.3 & 11 & 8.3 \\
\hline Dissatisfied & 10 & 17.9 & 10 & 7.6 \\
\hline Somewhat dissatisfied & 8 & 14.3 & 10 & 7.6 \\
\hline Neutral & 4 & 7.1 & 7 & 5.3 \\
\hline Somewhat satisfied & 5 & 8.9 & 19 & 14.4 \\
\hline Satisfied & 11 & 19.6 & 34 & 25.8 \\
\hline Very satisfied & 10 & 17.9 & 41 & 31.1 \\
\hline
\end{tabular}

4 
Table 4(on next page)

Categories Parents Perceive to be Most Influential to their Grief $(N=189)$

Table 4 - Categories Parents Perceive to be Most Influential to their Grief ( $N=189$ ) 
2 Table 4

3 Categories Parents Perceive to be Most Influential to their Grief ( $N=$ 4 189) Measure Frequency $\quad \%$ Creating Memories Respect 142 Hospital Stay Aftercare 125 75.1 Information 110 66.1 Autopsy

$86 \quad 45.5$

Birth Options

$84 \quad 44.4$

Other

$36 \quad 19.0$

$34 \quad 18.0$

5

$22 \quad 11.6$

